\title{
Do pandemics have an asymmetric effect on tourism in Italy?
}

\author{
Gizem Uzuner $^{1} \cdot$ Sudeshna Ghosh ${ }^{2}$
}

Accepted: 6 November 2020 / Published online: 16 November 2020

(c) Springer Nature B.V. 2020

\begin{abstract}
In this study, the asymmetric Granger causality relationship between tourist arrivals and world pandemic uncertainty index is examined by controlling inflation, consumer confidence index, and industrial production for the period 2000M1 and 2020M1 in Italy. To the best of our knowledge, the current study is one of the few studies to investigate the relationship between tourist arrivals and world pandemic uncertainty in an asymmetric framework. The empirical results show that using the Granger causality test in a linear framework causes bias results due to misspecification. Therefore, the study relies on asymmetric Granger causality test results which reveal that the positive shock of world pandemic uncertainty Granger causes a negative shock of tourist arrivals. It is suggested that international tourist arrivals are sensitive to external shocks such as pandemics and in such instances the government of the concerned country can insulate the tourism-service and hospitality industry against the shocks by developing strategies to promote full information between all stakeholders.
\end{abstract}

Keywords Pandemics · COVID-19 · Tourism · World uncertainty index · Inflation · Consumer confidence index $\cdot$ Industrial production $\cdot$ Italy

JEL Codes Z3 $\cdot$ E23 $\cdot$ E31

\section{Introduction}

In the middle of December 2019, the city of Wuhan in central China first witnessed the epidemic which is familiar today as COVID-19. The disease spread across all countries and the World Health Organization (WHO) declared a situation of a public health emergency at the international level. As far as the spread of the pandemic outside the Asian region

Gizem Uzuner

guzuner@gelisim.edu.tr

Sudeshna Ghosh

sudeshna.ghoshsent@outlook.com

1 Faculty of Economics, Administrative and Social Sciences, Istanbul Gelisim University, Istanbul, Turkey

2 Department of Economics, Scottish Church College, 1\&3 Urquhart Square, University of Calcutta, Kolkata, West Bengal 700006, India 
is concerned Italy in Europe followed by Spain are the worst hit. As of 31, March 2020 the highest number of deaths globally owing to COVID-19 was in Italy. The Director of WHO urged all nations to take preventive measures to contain the virus which includes the imposition of social distancing and quarantine. With increasing restrictions on mobility, the economy is hovering under uncertainty and income losses.

Since March 2020 the COVID-19 devasted the tourism industry, international tourism came to a standstill. Restrictions on travel, cancellation of flights, and closure of hotels have reduced the tourism business significantly. The Organization for Economic Cooperation and Development (OECD) fears that the pandemic would lead to a contraction of tourism industry around 60-80\% in 2020, (Tourism Policy Responses to the coronavirus, COVID-19, OECD 2020). Such downswings in tourism demand were also experienced during the periods of the global financial crisis in 2008 (World Tourism Organization and International Labour Organization 2013). Euromonitor International (2020) reports that though Italy is one of the world's top tourist destinations it witnessed shut down of $80 \%$ of its hotels by mid-March. An estimated 260 million booking in US\$ was canceled in Italy.

This paper attempts to explore how economic uncertainty related to the pandemics will affect the tourism industry in Italy. Ahir et al. (2018) developed a new measure related to the World Uncertainty Index popularly known as the World Pandemic Uncertainty Index (WPU). This new index namely the WPU is a sub-index of the World Uncertainty Index, it was formulated by counting the number of times the word "uncertainty" is stated in close proximity to pandemics in the Economic Intelligence country reports. According to Ahir et al. (2018) uncertainty related to the pandemic COVID-19 first rose in China and gradually spread across major economies of the world. Uncertainty around the epidemic is high in Italy, Spain, the USA, and the UK. Since historically nations have experienced close causal association between uncertainty and economic austerity the current study will explore the causality between pandemics related uncertainty and tourism in Italy, the worst-hit European country by COVID-19. According to World Travel and Tourism Council (WTTC) (2020), the total contribution of travel and tourism to GDP in Italy was $13 \%$ in 2019 , this was an increase of $2.2 \%$ from the previous years. Further, the sector contributes about $14.9 \%$ as far as the share of employment in the economy is concerned. However, in the event of the current pandemics crisis which generated economic uncertainty the WTTC (2020) reports that the loss of tourism and the travel industry as a share of GDP at the global level will be to the effect of US\$2.1 trillion in 2020. Further, the revenue generated from the tourism and travel industry in Italy is likely to decrease from 20.3 billion U.S. dollars in 2019 to around 11.2 billion U.S. dollars in 2020. It is well-established that consumers postpone their purchasing decisions in the events of uncertainty and economic crisis which leads to overall shrinkage of economic activity. The studies of Song and Lin (2010), Papatheodorou et al. (2010), Ritchie and Molinar (2010), Sheldon and Dwyer (2010), del Mar Alonso-Almeida and Bremser (2013), Ongan and Gozgor (2018), Singh et al. (2019) and Işık et al. (2019a, b) discuss that consumers demand for tourism shrink in the events of economic crisis. The Economic Policy Uncertainty index developed by Baker et al. (2016) is based upon three features: (1) coverage of newspaper on Economic Policy Uncertainty; (2) expectations about the tax code of future and (3) divergence among economic forecasters, was widely used in the literature to predict tourism demand, Gozgor and Ongan (2017), Demir and Ersan (2018) and Gozgor and Ongan (2017) are among the notable contributions.

The literature discusses a wide variety of methodologies that empirically verifies the adverse impact of the economic crisis on tourism demand. Sharma (2019) applied asymmetric autoregressive methods to explore the impacts of uncertainty on tourism 
demand for India over 2006Q1 to 2018 Q4. Perles-Ribes et al. (2016) applied non-linear econometric models to verify how uncertainty impacts tourism demand for Spain during 1970-2013. Uzuner et al. (2020) examined the causal association between tourism, economic policy uncertainty, migration, and fear originating from it and economic growth for the countries of France, Germany, the UK, and the USA over 1985Q1 to 2017Q4. Chisadza et al. (2020) explore how uncertainty impacts tourism in Africa by employing time series panel estimation techniques. Nevertheless, the existing literature lacks adequate empirical discussion between the causal link between world policy uncertainty and tourism. Hence this study is designed to explore a causal link between tourism and world policy uncertainty weighted by the impact of the pandemic thereby focusing upon the discussion on the new measure on world uncertainty by Ahir et al. (2018).

The motivation of the current study will add uniqueness to the extant literature because (i) it establishes the causal relationship between World Policy Uncertainty induced by pandemics and tourism. This new uncertainty measure has not been extensively used in the literature however owing to its strong correlation with the pandemics crisis it will be a good indicator for explaining causality between tourism and uncertainty owing to pandemics. The COVID-19 produced an immense wave in policy uncertainty and economic decision making. According to Baker et al. (2020) uncertainties related to the infectious epidemic impact the health care system, affect the process of social distancing, impact the market owing to lockdowns, and generates a shift in consumer spending behavior as business revives. The newly constructed quarterly measure of World uncertainty index covers a set of one hundred and forty-three countries, it provides a long-range of time series data, it is created by counting the word uncertainty related to pandemics from Economist Intelligence Unit. According to Ahir et al. (2018) the new index describes clearly the trends in uncertainty and it is highly correlated with economic policy uncertainty, risk, and market fluctuations. (ii) Unlike the earlier studies which did not take into consideration the occurrence of the possible nonlinearities in the underlying relationship across the series, we apply the novel asymmetric Granger causality methodology of Hatemi-J (2012). This methodology reduces the impact of the limited assumption of linearity and provides a more dependable and inclusive conclusion in the causal nexus between the variables. The linear Granger causality test assumes that the causal effect of positive and negative shocks is identical in magnitude. This assumption is very constricting because individuals react in a different way as far as the positive and negative shocks are concerned. The asymmetric causality analysis between World Uncertainty Index and tourism has a greater role in policymaking. It will enable policymakers to focus on the asymmetry that largely impacts tourism. Moreover, the existence of nonlinearity across the variables was tested by applying the Brock-Dechert-Scheinkman test (BDS test). (iii) By applying further Toda and Yamamoto (1995) Granger causality method, the current paper compares the causality association and verifies that the underlying causality is nonlinear. (iv) By focusing on a single country case study the present research allows for reflection of country-specific features and this will not comply with policymakers to apply 'all fit size policy' that often has an unknown bearing on the economy. (vi) It encompasses a wide-ranging time-series data from 2000M1 to2020M1 and (vii) to ensure a comprehensive analysis of the causality association between uncertainty and tourism the study has controlled for some important macroeconomic variables like inflation, industrial production proxy for the economic expansion and consumer confidence index. The paper henceforth is designed as follows Sect. 2 discusses the recent development in tourism literature related to uncertainty impacts, the data sets, choice of variables, and the methodology is delved upon 
in Sect. 3. Section 4 deals with the major empirical results and discussion, the policy implications are discussed in Sect. 5, the paper is finally concluded in Sect. 6.

\section{Review of literature}

\subsection{Uncertainty and tourism}

Wide-ranging literature explores how uncertainty impacts major macro-economic variables, for example, Brogaard and Detzel (2015) and Karnizova and Li (2014) explore the impact on stock markets; Aye (2018) and Chow et al. (2017) examine how economic policy uncertainty impacts housing prices. Arouri et al. (2014) and Bekiros et al. (2015) discuss how uncertainty impacts oil prices. The literature on the effects of uncertainty measured by the Economic Policy Uncertainty Index (EPU) formulated by Baker et al. (2016) agrees that EPU has adverse impacts on the various economic characteristics and policy decisions. The recent findings discuss that the impact of EPU on the varying set of macroeconomic factors is often asymmetric, for example, Divino and McAleer (2010), Bahmani-Oskooee and Saha (2019) and Sharma (2019).

The rising adverse impact of EPU on tourism has prompted researchers to include it as an additional variable in the tourism demand models apart from studying the impact of Gross National Product per capita, exchange rate behavior, consumer price index, international trade, energy consumption, financial expansion, consumer confidence index and consumer mood shocks, for example, Dragouni et al. (2016), Chatziantoniou et al. (2016) Işik et al. (2017), Dogru et al. (2019) and Işik et al. (2019a, b). Gozgor and Ongan (2017) using quarterly time-series data from 1998Q1 to 2015Q4 in the case of the USA obtains on the basis of a cointegrating model that EPU adversely affects tourism expenses. Tsui et al. (2018) study in the context of business tourism in New Zealand confirms the findings of Gozgor and Ongan (2017). Demir and Gozgor (2016) study in the context of vehicular mileage for the United States from 1987 to 2014 confirms the adverse impact of EPU on vehicular mileage. Using a tourism demand model Demir and Gözgör (2018) explores how the EPU index negatively affects outbound tourism for a panel set of fifteen countries Ongan and Gozgor (2018) based on quarterly data from 1996Q1 to 2015Q1 examines the impact of EPU on inbound tourist flows from Japan to the United States. The cointegrating results demonstrate that 1\% dispersion in EPU leads to declining Japanese tourist arrivals in the USA by $4.7 \%$ in the long-run Gozgor and Demir (2018) explores the impact of EPU on outbound travel expenditure for seventeen countries belonging to the developing and the developed region, the study concludes that the impact of EPU on outbound tourism is stronger for the developing regions. Işik et al. (2019b) based on monthly observations over January 1996 to September 2017, for tourist arrivals in the USA from Mexico and Canada, finds that tourists from Canada are more prone to cutting down of travel plans in the event of uncertainty compared to the Mexican travelers. Wu and Wu (2019) using the wavelength model explored the impact of EPU on tourist receipts in the countries of Greece, Portugal, Ireland, and Spain based on the annual frequency of observations over 1995 to 2015. The study obtains bidirectional causal association in the long-run between tourist receipts and EPU. The study thrusts upon the need for government involvement to introduce policies of expansionary tourism in the context when uncertainty recedes Akadiri et al.'s (2019) panel causality analysis over the period of 1995-2016 between EPU and tourist arrivals for countries Canada, France, Ireland, United States, Brazil, China, Germany, Chile, Japan, 
and South Korea produce mixed results. There exists bidirectional causality across tourist arrivals and EPU for Ireland, France, and the United States. Unidirectional causality is found in China, Brazil, Canada, and Germany and there is no causality behavior for Japan, South Korea, and Chile. The paper raises concerns over the feedback impact of EPU on tourism. Madanoglu and Ozdemir (2018) in the context of the hotel industry illustrate the negative impact of EPU for the United States. Khan et al. (2020) applying gravity model examines the association between inbound tourist flows to the United Kingdom and EPU, the full sample results show that EPU Granger causes inbound tourist inflows however for sub-samples tourist inflows positively impacts EPU. This is owing to the existence of structural changes in the model. The paper concludes that policymakers should concentrate on time-varying attributes to forecast tourist inflows. Nguyen et al. (2020) study show that EPU has multiple impacts on tourism, the paper concludes that during times of uncertainty tourists would cancel long destination travel plans and choose to holiday in nearby locations.

\subsection{Epidemics and tourism}

There are important contributions in the literature which explore the impact of epidemics on the tourism industry, for example, Zeng et al. (2005), McAleer et al. (2010), Yang et al. (2020), Sio-Chong and So (2020) and Karabulut et al. (2020). Zeng et al. (2005) discusses in the context of China how the SARS epidemic of 2003 adversely impacted tourism. The study recommended the need for appropriate planning and partnerships in tourism to expand the business as the uncertainty surrounding the epidemic recedes. McAleer et al. (2010) study observed the negative impact of SARS and Avian flu epidemic for inbound international tourist flows in Asia. The study concludes that the adverse impact of the SARS epidemic is more severe in deterring tourist arrivals in the Asian region. SioChong and So (2020) examines how the adversative behavior of climatic hazards, disease epidemics, and financial crisis reduced tourist inflows in the Chinese cities of Macao and Hong Kong. So, the thrust of policy implications as the study suggests is the need to plan for combating multiple categories of uncertainty. Christidis and Christodoulou (2020) discusses that travelling by air has a major role to play as far as the spread of COVID-19 at the global level is concerned. The paper concludes that the countries which had higher levels of communication and interactions with China gauged the risks at an earlier stage and accordingly took firm measures to contain the spread of the virus. So, these countries experienced lesser cases of susceptibility to the virus. However, the countries which initially felt that the levels of risk were low turned out to be the countries with high rates of infection larger even than China. The major countries which were in this category were the USA, Spain and Italy Yang et al. (2020) studied the impact of the COVID-19 on the tourism industry based on the dynamic stochastic general equilibrium model. The dynamic stochastic general equilibrium model analyzed the nature of the severity of the pandemics in the tourism industry. Karabulut et al. (2020) using the World Uncertainty Index computed by Ahir et al. (2018), demonstrates how pandemics impacted tourism in both the low-and high-income countries. The study concludes that the adverse impact of pandemics is intense in low-income countries. The study of Karabulut et al. (2020) is among the few research contributions that utilized the new data sets of Ahir et al. (2018) apart from this present study.

The important conclusion that emerged from the foregoing discussion is that in today's age of globalization uncertainty emanating in any part of the globe impacts economic 
functioning in other parts of the globe. In the advent of uncertainty, consumers switch their expenditure plans away from luxury commodities. The vacation plans of the consumers get largely affected which is a luxury commodity, this has a huge negative bearing upon tourism. However, the literature mainly explores the impact and association of uncertainty upon tourism in linear models. According to Anoruo (2011) examination of causality properties in a linear framework may be misleading because often the time series of observations show nonlinear behavior. Further Granger and Yoon (2002) discussion on the idea of hidden cointegration illustrates the importance of nonlinearities underlying time-series observations. The present research tries to fill the current research gap by exploring causality behavior in the nonlinear framework. The study explores (i) whether there is a causal association between World Pandemics Induced Uncertainty Index and inbound tourist flows? (ii) The study further explores whether there is a difference in the causal association between the negative and the positive changes.

\section{Methodology, choice of variables and data sets}

\subsection{Theoretical framework}

The empirical literature discusses that there exists a significant association between uncertainty and tourism, the Eq. (1) illustrates the baseline model that the present study attempts to explore,

$$
T A=f(C C I, I N F, I P, W P U)
$$

where TA indicates a number of tourist arrivals, CCI shows the index of consumer confidence, INF indicates inflation, IP denotes industrial production and WPU is World Pandemics Related Uncertainty Index.

\subsection{Data and description of variables}

The data utilized for the current research in the context of Italy consists of monthly observations running from $2000 \mathrm{M} 1$ to $2020 \mathrm{M} 1$. The dependent variable is TA which is thenumber of tourist arrivals, the data source is the EUROSTAT database. ${ }^{1}$ The TA data is highly seasonal; hence the data is seasonally adjusted using the Census X-12 method and also we take the logarithm of the TA. Data on INF which measures inflation and IP which measures industrial production respectively is obtained from the Eurostat database. Inflation is measured by the consumer price index (CPI) indexed in 2015 as the base year. It measures the change in the prices of a basket of consumer goods. The industrial production (IP) shows the output and activity of the industry sector. Data on CCI which denotes the Consumer Confidence Index is obtained from the OECD database (OECD 2020). ${ }^{2}$ The CCI denotes the future spending behavior of the households based on their expectations about the financial situation, an index above 100 indicates that consumers have high confidence that the economy will expand, the value of the index below 100 indicates that consumers are not optimistic about the economy. Data on WPU which denotes World Pandemic Uncertainty

\footnotetext{
1 URL: https://ec.europa.eu/eurostat/web/tourism/data/database. Access date: May, 2020.

2 Access date: May, 2020.
} 
Index is obtained from Ahir et al. (2018) ("World Uncertainty Index"). ${ }^{3}$ The WPU measures uncertainty induced by pandemics, it is constructed by counting the number of times uncertainty (the word) associated with pandemics is found in the Economist Intelligence Unit (EIU) country reports. A higher number implies higher uncertainty related to pandemics and contraries. Originally, WPU data is available in quarterly frequency, but it is converted to its monthly frequency observations by taking the quadratic average to bring consistency with data sets of other variables based on monthly frequency observations.

\subsection{Methodology}

The estimation begins with a preliminary overview of the descriptive statistics and the correlation analysis which demonstrates the basic features of the underlying time-series observations. Further, the Brock-Dechert-Scheinkman (BDS) (1996) nonlinearity test was applied to explore whether the relationship between tourist arrivals, WPU, IP, CCI, INF is linear or non-linear. Next, we explore the Granger causality test to see the causality behaviour of the underlying observations by applying the Toda and Yamamoto (1995) Granger Causality Method. However, such statistical tests implicitly suppose that the causal behaviour of the positive and negative shocks are identical in magnitude and impact. Alternatively speaking it does not detect the asymmetries in the series. This underlying assumption is too limiting because an individual's response to positive and negative shocks are not always identical. To explore potential asymmetric causality the current paper adopts the recent Hatemi-J (2012) Asymmetric Granger causality tests.

\subsubsection{Brock-Dechert-Scheinkman (BDS) test}

The time series literature discusses many statistical tests to examine the nonlinearity relationships for example Brooks (1996), Hinich and Patterson (1985) and Brock et al. (1996) (BDS) test. This paper applies the BDS test because it is widely recommended as a test for denoting misspecification in the model as it exhibits high statistical power in detecting whether there is linearity or not compared to the other class of tests. The BDS test is applied to detect misspecification to the residuals of models fitted in ARIMA, ARCH and GARCH. The null hypothesis of the BDS is the data are independently and identically distributed if the null hypothesis is not rejected then the original linear specification hypothesis is not rejected.

\subsubsection{Toda and Yamamoto (1995) Granger causality method}

The Toda and Yamamoto (1995) Granger Causality Method produces robust causality results based on the Wald Test Statistics even when the series are integrated of order I(0), I(1) or mixed order, I(0) /I(1). The Toda and Yamamoto (1995) Granger Causality Test has better estimation-based merits than the earlier conventional Granger Causality Tests. This method is developed on the vector regressive structure (VAR) structure $\left(k+d_{\max }\right)$ here $\mathrm{k}$ is the optimal order in the VAR system and $d_{\max }$ is the optimal order of integration. The Toda and Yamamoto (1995) Granger Causality test equations can be shown as:

${ }^{3}$ URL: https://worlduncertaintyindex.com/data/. Access date: May, 2020. 


$$
\begin{aligned}
T A_{t}= & \alpha_{0}+\sum_{i=1}^{k} \alpha_{1 i} T A_{t-i}+\sum_{j=k+1}^{d m a x} \alpha_{2 i} T A_{t-j}+\sum_{i=1}^{k} \beta_{1 i} C C I_{t-i} \\
& +\sum_{j=k+1}^{b m a x} \beta_{2 i} C C I_{t-j}+\sum_{i=1}^{k} \delta_{1 i} I N F_{t-i}+\sum_{j=k+1}^{d m a x} \delta_{2 i} I N F_{t-j}+\sum_{i=1}^{k} \lambda_{1 i} I P_{t-i} \\
& +\sum_{j=k+1}^{d \max } \lambda_{2 i} I P_{t-j}+\sum_{i=1}^{k} \sigma_{1 i} W P U_{t-i}+\sum_{j=k+1}^{b m a x} \sigma_{2 i} W P U_{t-j}+\vartheta_{1 t} \\
C C I_{t}= & \beta_{0}+\sum_{i=1}^{k} \beta_{1 i} C C I_{t-i}+\sum_{j=k+1}^{d m a x} \beta_{2 i} C C I_{t-j+} \sum_{i=1}^{k} \alpha_{1 i} T A_{t-i} \\
& +\sum_{j=k+1}^{d m a x} \alpha_{2 i} T A_{t-j}+\sum_{i=1}^{k} \delta_{1 i} I N F_{t-i}+\sum_{j=k+1}^{d m a x} \delta_{2 i} I N F_{t-j} \\
& +\sum_{i=1}^{k} \lambda_{1 i} I P_{t-i}+\sum_{j=k+1}^{d m a x} \lambda_{2 i} I P_{t-j}+\sum_{i=1}^{k} \sigma_{1 i} W P U_{t-i} \\
& +\sum_{j=k+1}^{d m a x} \sigma_{2 i} W P U_{t-j}+\vartheta_{2 t}
\end{aligned}
$$$$
I N F_{t}=\delta_{0}+\sum_{i=1}^{k} \delta_{1 i} I N F_{t-i}+\sum_{j=k+1}^{d \max } \delta_{2 i} I N F_{t-j}+\sum_{i=1}^{k} \beta_{1 i} C C I_{t-i}
$$$$
+\sum_{j=k+1}^{d \max } \beta_{2 i} C C I_{t-j+} \sum_{i=1}^{k} \alpha_{1 i} T A_{t-i}+\sum_{j=k+1}^{d \max } \alpha_{2 i} T A_{t-j}+\sum_{i=1}^{k} \lambda_{1 i} I P_{t-i}
$$$$
+\sum_{j=k+1}^{d m a x} \lambda_{2 i} I P_{t-j}+\sum_{i=1}^{k} \sigma_{1 i} W P U_{t-i}+\sum_{j=k+1}^{d \max } \sigma_{2 i} W P U_{t-j}+\vartheta_{3 t}
$$$$
I P_{t}=\lambda_{0}+\sum_{i=1}^{k} \lambda_{1 i} I P_{t-i}+\sum_{j=k+1}^{d \max } \lambda_{2 i} I P_{t-j}+\sum_{i=1}^{k} \delta_{1 i} I N F_{t-i} \sum_{j=k+1}^{d \max } \delta_{2 i} I N F_{t-j}
$$$$
+\sum_{i=1}^{k} \beta_{1 i} C C I_{t-i}+\sum_{j=k+1}^{d \max } \beta_{2 i} C C I_{t-j+} \sum_{i=1}^{k} \alpha_{1 i} T A_{t-i}+\sum_{j=k+1}^{d \max } \alpha_{2 i} T A_{t-j}
$$$$
+\sum_{i=1}^{k} \sigma_{1 i} W P U_{t-i}+\sum_{j=k+1}^{d \max } \sigma_{2 i} W P U_{t-j}+\vartheta_{4 t}
$$ 


$$
\begin{aligned}
W P U_{t}= & \sigma_{0}+\sum_{i=1}^{k} \sigma_{1 i} W P U_{t-i}+\sum_{j=k+1}^{d \max } \sigma_{2 i} W P U_{t-j}+\sum_{i=1}^{k} \lambda_{1 i} I P_{t-i} \\
& +\sum_{j=k+1}^{d m a x} \lambda_{2 i} I P_{t-j}+\sum_{i=1}^{k} \delta_{1 i} I N F_{t-i}+\sum_{j=k+1}^{d m a x} \delta_{2 i} I N F_{t-j}+\sum_{i=1}^{k} \beta_{1 i} C C I_{t-i} \\
& +\sum_{j=k+1}^{d m a x} \beta_{2 i} C C I_{t-j}+\sum_{i=1}^{k} \alpha_{1 i} T A_{t-i}+\sum_{j=k+1}^{d m a x} \alpha_{2 i} T A_{t-j}+\vartheta_{5 t}
\end{aligned}
$$

Here $\alpha_{i}, \beta_{i}, \delta_{i}, \lambda_{i}$ and $\sigma_{i}$ are parameters of lagged TA, CCI, INF, IP and WPU respectively. The significant coefficients of the explanatory variables in Eq. (2) for example indicate Granger causality from the set of explanatory variables to TA and likewise for the Eqs. (3)--(6). In Eq. (2) there is unidirectional causality from CCI to TA if $\beta_{i} \neq 0 \forall_{\mathrm{I}}$ likewise for the other coefficients the same explanation holds true in the other equations.

\subsubsection{Hatemi-J (2012) asymmetric Granger causality tests}

According to Hatemi-J (2012) asymmetric Granger Causality test shows that the causal behavior of the positive impact of the shock is not identical to the causal behavior of the negative impact of the shocks. Hatemi-J (2012) postulated a null hypothesis by putting zero restrictions on the given parameters in an autoregressive framework, the rejection of the null hypothesis implies the existence of Granger Causality.

To test for causality for positive and negative impacts of the variables namely TA, WPU, for example, the cumulative sums can be expressed as below:

$$
\begin{aligned}
& {\left[\begin{array}{c}
T A_{t} \\
W P U_{t}^{+}
\end{array}\right]=\left[\begin{array}{l}
\alpha_{10} \\
\alpha_{20}
\end{array}\right]+\left[\begin{array}{cc}
\sum_{i=1}^{k} \alpha_{1 i} & \sum_{j=1}^{m} \beta_{1 j} \\
\sum_{i=1}^{k} \alpha_{2 i} & \sum_{j=1}^{m} \beta_{2 j}
\end{array}\right] \times\left[\begin{array}{c}
W P U_{t-i}^{+} \\
T A_{t-i}
\end{array}\right]+\left[\begin{array}{c}
\gamma_{1 t}^{+} \\
\gamma_{2 t}^{+}
\end{array}\right]} \\
& {\left[\begin{array}{c}
T A_{t} \\
W P U_{t}^{-}
\end{array}\right]=\left[\begin{array}{c}
\alpha_{10} \\
\alpha_{20}
\end{array}\right]+\left[\begin{array}{cc}
\sum_{i=1}^{k} \alpha_{1 i} & \sum_{j=1}^{m} \beta_{1 j} \\
\sum_{i=1}^{k} \alpha_{2 i} & \sum_{j=1}^{m} \beta_{2 j}
\end{array}\right] \times\left[\begin{array}{c}
W P U_{t-i}^{-} \\
T A_{t-i}
\end{array}\right]+\left[\begin{array}{l}
\gamma_{1 t}^{-} \\
\gamma_{2 t}^{-}
\end{array}\right]}
\end{aligned}
$$

Here $T A_{t}$ are $W P U_{t}$ are the variables whose causality will be explored, $\mathrm{k}$ and $\mathrm{m}$ are the lag orders, $\gamma_{1 t}^{+}, \gamma_{1 t}^{-}, \gamma_{2 t}^{+}$and $\gamma_{2 t}^{-}$denote the residuals. The null hypothesis for positive causality is $W P U_{t}^{+}$does not cause $T A_{t}$ while the null hypothesis for negative causality is $W P U_{t}^{-}$does not cause $T A_{t}$. Similar equations can be tested for other explanatory variables.

Also, The Hatemi-J criterion (HJC) used to determine the optimal lag order (Hatemi-J 2003, 2008).

$$
H J C=\ln (|\hat{D}|)+j\left(\frac{n^{2} \ln T+2 n^{2} \ln (\ln T)}{2 T}\right), \quad j=0,1, \ldots,
$$

where $|\hat{D}|$ is a determinant of the obtained variance-covariance matrix of the error terms in the VAR model with lag order $j, n$ represents the number of equations, and $T$ represents the 
Table 1 Summary statistics and the correlation analysis

\begin{tabular}{|c|c|c|c|c|c|}
\hline & TA & CCI & INF & IP & WPU \\
\hline \multicolumn{6}{|c|}{ A) Summary statistics } \\
\hline Observations & 241 & 241 & 241 & 241 & 241 \\
\hline Mean & 5.8085 & 99.9851 & 1.7167 & 113.1137 & 0.1644 \\
\hline Median & 5.8176 & 100.1818 & 1.8735 & 108.3000 & 0.0000 \\
\hline Maximum & 6.1110 & 102.5156 & 4.0786 & 134.6000 & 7.0207 \\
\hline Minimum & 5.4859 & 96.9582 & -0.5587 & 96.1000 & -1.9059 \\
\hline Std. Dev & 0.1376 & 1.2201 & 1.0626 & 11.7845 & 0.7192 \\
\hline Skewness & -0.1292 & -0.4225 & -0.2278 & 0.1875 & 6.3383 \\
\hline Kurtosis & 2.2756 & 2.8569 & 2.1268 & 1.4316 & 51.0231 \\
\hline Jarque-Bera & $6.1509 * *$ & $7.3756^{* *}$ & $9.7398 *$ & $26.1134^{*}$ & $24,771.9100 *$ \\
\hline Probability & 0.0462 & 0.0250 & 0.0077 & 0.0000 & 0.0000 \\
\hline Sum & 1393.7760 & $24,096.4100$ & 413.7155 & $27,260.4000$ & 39.6307 \\
\hline Sum Sq. Dev & 4.5232 & 357.2634 & 271.0133 & $33,329.7000$ & 124.1239 \\
\hline \multicolumn{6}{|c|}{ B) Correlation analysis } \\
\hline TA & 1.0000 & & & & \\
\hline $\mathrm{CCI}$ & $-0.3842^{*}$ & 1.0000 & & & \\
\hline INF & $-0.5873^{*}$ & -0.0276 & 1.0000 & & \\
\hline IP & $-0.7264 *$ & 0.5665 & $0.6449 *$ & 1.0000 & \\
\hline WPU & -0.0495 & 0.0191 & 0.0315 & 0.0518 & 1.0000 \\
\hline
\end{tabular}

$*, * *$ Show the significance level at 0.01 and 0.05

number of observations in the VAR model. The null hypothesis of non-Granger causality can be tested using the modified version of WALD statistics (Hatemi-J 2012). ${ }^{4}$

\section{Empirical results and discussions}

Table 1 reports the summary statistics of the selected variables with their correlation analysis results. According to the table, the tourist arrivals are less volatile while the industrial production is more volatile than the other variables. Most of the variables are left-skewed with positive kurtosis which leads to non-normal distribution. Besides that, the non-normal distribution properties of the variables are also confirmed by using the Jarque-Bera statistic. Furthermore, Table 3 shows the Pearson correlation coefficient results between the selected variables. Tourist arrivals are negatively correlated with the consumer confidence index, inflation and industrial production. However, there is no significant correlation between the explanatory variables. ${ }^{5}$

The Wald test result has a non-standard distribution if the variables in a VAR model are integrated or cointegrated. As a result, the implication of the conventional Granger

\footnotetext{
4 For detail information interested reader should see Hatemi-J (2012).

5 See the Table 4: There is no multicollinearity between the variables, since the Variance Inflation Factor (VIF) is less than 10.
} 
Table 2 Toda-Yamamoto Granger causality test results

\begin{tabular}{lll}
\hline Hypothesis & Chi-square P-value & Decision \\
\hline CCI $\neq>$ TA & 0.97950 .8062 & CCI $\neq>$ TA \\
INF $\neq>$ TA & 1.28370 .7330 & INF $\neq>$ TA \\
IP $\neq>$ TA & 1.11940 .7724 & IP $\neq>$ TA \\
WPU $\neq>$ TA & 4.68280 .1966 & WPU $\neq>$ TA \\
TA $\neq>$ CCI & 1.85930 .6021 & TA $\neq>$ CCI \\
INF $\neq>$ CCI & 5.50840 .1381 & INF $\neq>$ CCI \\
IP $\neq>$ CCI & $7.4467 * * * 0.0589$ & IP $\rightarrow$ CCI \\
WPU $\neq>$ CCI & 0.96470 .8098 & WPU $\neq>$ CCI \\
TA $\neq>$ INF & $1.8593 * * * 0.0991$ & TA $\rightarrow$ INF \\
CCI $\neq>$ INF & 3.66990 .2994 & $\mathrm{CCI} \neq>$ INF \\
IP $\neq>$ INF & 4.52880 .2097 & IP $\neq>$ INF \\
WPU $\neq>$ INF & 0.61030 .8941 & WPU $\neq>$ INF \\
TA $\neq>$ IP & $10.5768 * * 0.0142$ & TA $\rightarrow$ IP \\
CCI $\neq>$ IP & 1.35110 .7170 & CCI $\neq>$ IP \\
INF $\neq>$ IP & 5.98010 .1126 & INF $\neq>$ IP \\
WPU $\neq>$ IP & 0.89670 .8262 & WPU $\neq>$ IP \\
TA $\neq>$ WPU & 3.17990 .3647 & TA $\neq>$ WPU \\
CCI $\neq>$ WPU & 3.86570 .2763 & $\mathrm{CCI} \neq>$ WPU \\
INFI $\neq>$ WPU & 0.94810 .8138 & INFI $\neq>$ WPU \\
IP $\neq>$ WPU & 0.39180 .9419 & IP $\neq>$ WPU \\
\hline
\end{tabular}

The symbols " $\neq>$ and $\rightarrow$ " denote the non-Granger causality and unidirectional Granger causality relationship for the selected variables

$* *, * * *$ Indicate the 0.05 and 0.10 significance level. The optimal lag is selected as 3 by using SIC

\begin{tabular}{llll}
\hline Variable & BDS statistic & Standard error & Probability \\
\hline TA & $0.1272^{*}$ & 0.0032 & 0.0000 \\
CCI & $0.1901^{*}$ & 0.0046 & 0.0000 \\
INF & $0.1723^{*}$ & 0.0031 & 0.0000 \\
IP & $0.1782^{*}$ & 0.0026 & 0.0000 \\
WPU & $0.1525^{*}$ & 0.0100 & 0.0000 \\
\hline
\end{tabular}

*Denotes significance level at 0.01 . The number of dimensions is 2

causality approach is required to test for unit root and cointegration. However, the Toda-Yamomata Granger causality technique overcomes these pre-testing procedures by estimating the VAR $(p+d)$ model with level data, $d$ is the maximum integrated order of the variables, ${ }^{6}$ and $p$ is the optimal lag length. Due to these advantages, the study employs the Toda-Yamamoto Granger causality test to investigate the existence of Granger causality

\footnotetext{
${ }^{6}$ In this study, d determined as a 1 by using Augmented Dickey Fuller and Zivot Andrews unit root tests. For brevity, the unit root tests are eliminated. The unit root tests are available upon request.
} 
Table 4 Asymmetric causality test

\begin{tabular}{|c|c|c|c|}
\hline Hypothesis & Fisher statistic & $\mathrm{P}$-value & Decision \\
\hline $\mathrm{WPU}^{+} \neq>\mathrm{TA}^{+}$ & 1.896 & 0.388 & $\mathrm{WPU}^{+} \neq>\mathrm{TA}^{+}$ \\
\hline $\mathrm{WPU}^{+} \neq>\mathrm{TA}^{-}$ & $9.537 *$ & 0.008 & $\mathrm{WPU}^{+} \rightarrow \mathrm{TA}^{-}$ \\
\hline $\mathrm{WPU}^{-} \neq>\mathrm{TA}^{-}$ & 0.446 & 0.800 & $\mathrm{WPU}^{-} \neq>\mathrm{TA}^{-}$ \\
\hline $\mathrm{WPU}^{-} \neq>\mathrm{TA}^{+}$ & 0.989 & 0.610 & $\mathrm{WPU}^{-} \neq>\mathrm{TA}^{+}$ \\
\hline $\mathrm{TA}^{+} \neq>\mathrm{WPU}^{+}$ & 0.669 & 0.716 & $\mathrm{TA}^{+} \neq>\mathrm{WPU}^{+}$ \\
\hline $\mathrm{TA}^{+} \neq>\mathrm{WPU}^{-}$ & 0.483 & 0.785 & $\mathrm{TA}^{+} \neq>\mathrm{WPU}^{-}$ \\
\hline $\mathrm{TA}^{-} \neq>\mathrm{WPU}^{-}$ & 1.619 & 0.445 & $\mathrm{TA}^{-} \neq>\mathrm{WPU}^{-}$ \\
\hline $\mathrm{TA}^{-} \neq>\mathrm{WPU}^{+}$ & 0.717 & 0.699 & $\mathrm{TA}^{-} \neq>\mathrm{WPU}^{+}$ \\
\hline $\mathrm{INF}^{+} \neq>\mathrm{TA}^{+}$ & 0.122 & 0.941 & $\mathrm{INF}^{+} \neq>\mathrm{TA}^{+}$ \\
\hline $\mathrm{INF}^{+} \neq>\mathrm{TA}^{-}$ & 0.429 & 0.807 & $\mathrm{INF}^{+} \neq>\mathrm{TA}^{-}$ \\
\hline $\mathrm{INF}^{-} \neq>\mathrm{TA}^{-}$ & 3.746 & 0.154 & $\mathrm{INF}^{-} \neq>\mathrm{TA}^{-}$ \\
\hline $\mathrm{INF}^{-} \neq>\mathrm{TA}^{+}$ & 3.472 & 0.176 & $\mathrm{INF}^{-} \neq>\mathrm{TA}^{+}$ \\
\hline $\mathrm{TA}^{+} \neq>\mathrm{INF}^{+}$ & 0.485 & 0.785 & $\mathrm{TA}^{+} \neq>\mathrm{INF}^{+}$ \\
\hline $\mathrm{TA}^{+} \neq>\mathrm{INF}^{-}$ & $5.086^{* * * *}$ & 0.079 & $\mathrm{TA}^{+} \rightarrow \mathrm{INF}^{-}$ \\
\hline $\mathrm{TA}^{-} \neq>\mathrm{INF}^{-}$ & 1.675 & 0.433 & $\mathrm{TA}^{-} \neq>\mathrm{INF}^{-}$ \\
\hline $\mathrm{TA}^{-} \neq>\mathrm{INF}^{+}$ & 1.200 & 0.549 & $\mathrm{TA}^{-} \neq>\mathrm{INF}^{+}$ \\
\hline $\mathrm{IP}^{+} \neq>\mathrm{TA}^{+}$ & 3.217 & 0.200 & $\mathrm{IP}^{+} \neq>\mathrm{TA}^{+}$ \\
\hline $\mathrm{IP}^{+} \neq>\mathrm{TA}^{-}$ & 0.341 & 0.843 & $\mathrm{IP}^{+} \neq>\mathrm{TA}^{-}$ \\
\hline $\mathrm{IP}^{-} \neq>\mathrm{TA}^{-}$ & 0.079 & 0.961 & $\mathrm{IP}^{-} \neq>\mathrm{TA}^{-}$ \\
\hline $\mathrm{IP}^{-} \neq>\mathrm{TA}^{+}$ & $5.265^{* * *}$ & 0.072 & $\mathrm{IP}^{-} \rightarrow \mathrm{TA}^{+}$ \\
\hline $\mathrm{TA}^{+} \neq>\mathrm{IP}^{+}$ & 1.574 & 0.455 & $\mathrm{TA}^{+} \neq>\mathrm{IP}^{+}$ \\
\hline $\mathrm{TA}^{+} \neq>\mathrm{IP}^{-}$ & 0.757 & 0.685 & $\mathrm{TA}^{+} \neq>\mathrm{IP}^{-}$ \\
\hline $\mathrm{TA}^{-} \neq>\mathrm{IP}^{-}$ & 0.508 & 0.776 & $\mathrm{TA}^{-} \neq>\mathrm{IP}^{-}$ \\
\hline $\mathrm{TA}^{-} \neq>\mathrm{IP}^{+}$ & 3.187 & 0.168 & $\mathrm{TA}^{--} \neq>\mathrm{IP}^{+}$ \\
\hline $\mathrm{CCI}^{+} \neq>\mathrm{TA}^{+}$ & 0.375 & 0.829 & $\mathrm{CCI}^{+} \neq>\mathrm{TA}^{+}$ \\
\hline $\mathrm{CCI}^{+} \neq>\mathrm{TA}^{-}$ & $10.244^{* * *}$ & 0.006 & $\mathrm{CCI}^{+} \rightarrow \mathrm{TA}^{-}$ \\
\hline $\mathrm{CCI}^{-} \neq>\mathrm{TA}^{-}$ & 1.382 & 0.501 & $\mathrm{CCI}^{-} \neq>\mathrm{TA}^{-}$ \\
\hline $\mathrm{CCI}^{-} \neq>\mathrm{TA}^{+}$ & 2.092 & 0.351 & $\mathrm{CCI}^{-} \neq>\mathrm{TA}^{+}$ \\
\hline $\mathrm{TA}^{+} \neq>\mathrm{CCI}^{+}$ & 0.371 & 0.831 & $\mathrm{TA}^{+} \neq>\mathrm{CCI}^{+}$ \\
\hline $\mathrm{TA}^{+} \neq>\mathrm{CCI}^{-}$ & 0.991 & 0.609 & $\mathrm{TA}^{+} \neq>\mathrm{CCI}^{-}$ \\
\hline $\mathrm{TA}^{-} \neq>\mathrm{CCI}^{-}$ & $8.254 * * *$ & 0.016 & $\mathrm{TA}^{-} \rightarrow \mathrm{CCI}^{-}$ \\
\hline $\mathrm{TA}^{-} \neq>\mathrm{CCI}^{+}$ & 1.431 & 0.489 & $\mathrm{TA}^{-} \neq>\mathrm{CCI}^{+}$ \\
\hline
\end{tabular}

The symbols " $\neq>$ and $\rightarrow$ " denote the non-Granger causality and unidirectional Granger causality relationship for the selected variables

$* * * * *$ Indicate the 0.05 and 0.10 significance level. The optimal lag is selected as 3 by using Hatemi-J Criterion (HJC)

relation between the variables. Table 2 present the Toda-Yamamoto Granger causality results. The findings show that there is a unidirectional Granger causality running from tourist arrivals to industrial production. This result supports the tourism-induced growth hypothesis for Italy. It means that tourism arrival is a good predictor of industrial production. This is consistent with the study of Shi et al. (2020), Akadiri and Akadiri (2019) and Sokhanvar (2019). Also, there is a unidirectional Granger causality relationship from tourist arrivals to inflation. Furthermore, this study found a unidirectional Granger causality from industrial production to consumer confidence index. This indicates that the consumer 
confidence index can be predicted by using the past and current values of industrial production. However, there is no Granger causality relation between world pandemic uncertainty and tourist arrivals.

This study used the BDS test to check the robustness of the Granger causality test results. In addition, it is also used to check nonlinearity in the residuals of the dynamic relationship of the aforementioned variables equations. Table 3 presents the BDS test results which reveal the nonlinearity in the variables. It means that the results of linear Granger causality tests will be biased due to the misspecification. For this reason, we performed the asymmetric Granger causality test. The results of the asymmetric Granger causality are presented in Table 4. The result indicates a positive shock of world pandemic uncertainty Granger cause to the negative shock of tourist arrivals in Italy. This result supports the forecast of UNWTO (2020) and the study of Karabulut et al. (2020), Rosselló et al. (2017) Gössling et al. (2020), Ghosh (2020) and Kuo et al. (2008). Besides that, there is a Granger causality relation from a positive shock of tourist arrivals to negative shock in inflation. This may be explained by the dynamics between tourist arrivals and the exchange rate. Interestingly, a negative shock in industrial production Granger causes positive shock in tourist arrivals. Moreover, the results show that there is a unidirectional Granger causality relationship from the positive shock of consumer confidence index to the negative shock of tourist arrivals. Also, a negative shock in tourist arrivals Granger causes negative shock in the consumer confidence index. The asymmetric Granger causality exists from the negative shock of tourist arrivals to negative shock of consumer confidence index in Italy.

\section{Policy implications}

According to World Travel and Tourism Council (2020) expected timely announcements for medical solutions to combat the virus is still highly uncertain. The availability of vaccines is ambiguous and its successes are crucially dependent on clinical trials. Against this backdrop long-run strategic action plans needs to be formulated to combat challenges of tourism in the COVID-19 situation and also in the post pandemics situation. Governments in most countries are announcing fiscal packages to boost tourism. These include tax incentives, incentives to make investments in touchless tourism economy, promotion of sanitization activities and allowing companies to carry forward the recent losses. For long-term policy planning relating to tourism expansion in the post COVID-19 situation the thrust of emphasis should be upon social distancing, strategic shifts in hospitality services should be made, it should be oriented towards contactless services, encouraging of self-services, use of automation services for cleaning in hotels and airports should be increasingly practiced. Proper coordination of the government and major stakeholders in tourism will help in faster opening up of tourism. Recovery road maps can be built for the sectors which are the hardest hit relating to the hotel and hospitality industries. Constant dialogues can help in generating efficient mechanisms to put the tourism and hospitality industry on the path of sustained recovery. For lifting travel bans and ensuring travellers safety cross country dialogues are necessary focussing on the health situation of the concerned countries. Innovations, digital transformation like development of safety apps will generate positive signals which will instil consumer confidence and thereby expand tourism. Tourists needs to be freed from the anxiety of travelling and this can be done when private tour operators following official guidelines place new norms of hygiene, safety and testing methods. For effective recovery of the tourism sector policy initiative should be towards removing 
information gap so that the tourists have timely information on the COVID-19 related situation of a particular country. Removing information asymmetry goes in the long way to build trust which is the key to the successful business relationship across consumers and producers. Efforts needs to be put to build market confidence among the tourists. The World Travel and Tourism Council (2020) has suggested the following best practices for rapid and sustained recovery of the tourism sector: wider use of technology in fulfilling the process of visa requirements- this can be achieved through cross-country dialogues; for enhanced security in travelling along with safe travelling the framework of integrated biometrics needs to be developed. Close integration is required across various mode of transports within a country so that the health and safety of the international travellers can be constantly monitored. Visitors must be constantly updated on the country situation as far as the risks of the diseases and terror attacks are concerned. This can be effectively done through the digital system. Regulations must be developed on data privacy requirements of the tourists at the global level. Adequate research is still lacking on developing a single identity tourism database for safe and hassle-free travelling.

As far as the short-run policy measures are concerned the OECD (2020) stresses on the need to diversify the markets associated with tourism. The OECD (2020) further stresses on the need for substantial investments in digitalization and development of market intelligence system. Governments of all countries should develop strategies to promote tourism across all levels and not only international tourism. In fact, some countries are considering to put the tourism agenda as a part of the national emergency system and adopting the Sustainable Development Agenda. Consistent dialogues are required between medical professionals and tour operators and others associated with tourism business to facilitate tourism and travel in the 'New Normal' situation. In times of the 'New Normal' the urgency is to adapt to the changing needs and amend the earlier practices by focussing on health and sanitation and social distancing to protect both employees and tourists. Constant awareness programmes on touchless practices will enable travellers to gain confidence in travelling. Methods must be developed for constant test procedures to isolate workers and tourists with probable symptoms.

According to the reports of the OECD (2020) as far as Italy is concerned the government has adopted certain pro-tourism measures as of the following: scope of providing extraordinary allowances to all workers associated with tourism so as to mitigate the adverse impacts of the spread of the virus. A package of fiscal incentives is announced for workers in tourism sector, particularly in theatres, museums, restaurants, spas and amusements parks. The Ministry of Cultural Heritage and Activities and Tourism have announced provision of emergency funds to workers associated with tourism. The constant endeavour of the government of the country is towards safe tourism which is built trough adoption of new practices.

\section{Conclusion}

In this study, the Granger causality relationship between tourist arrivals and world pandemic uncertainty index is examined by controlling inflation, consumer confidence index, and industrial production index by using Toda-Yamomata Granger causality and Hatemi-J (2012) Asymmetric Granger causality test for the period 2000M1 and 2020M1 in Italy. According to the Toda-Yamomata Granger causality test, there is no existence of Granger 
causality relationship from world pandemic uncertainty to tourist arrivals. The BDS test applied to check the robustness of the result, The BDS test also confirmed the Jarque-Bera statistic results of the non-normal distribution of the variables. As the nonlinear relationship exists between the variables, the study relied on the results Hatemi-J (2012) Asymmetric Granger causality test.

The asymmetric Granger causality test reveals that there is a unidirectional Granger causality relationship from the positive shock of world pandemic uncertainty to the negative shock of tourist arrivals in Italy. This indicated that the world pandemic uncertainty is a good predictor of tourist arrivals. Tourists need to ensure that destinations to visit must be low-risk destinations to reduce untimely deaths, which is the primary reason in deterring international travel. Hence, the current study thrust upon the need for policymaker's attention in considering the world pandemic uncertainty index as a predictor of tourist arrivals besides the other prevalent macroeconomic variables.

The crucial impression that the present research attempts to make is that the future effect of pandemics on the economy and the tourism economy in particular largely surrounds the uncertainty that pandemics generate. The uncertainties in policy prescriptions may create a feedback impact on consumers confidence which adversely impacts the travel plans. To boost the tourism industry to its earlier path of expansive growth the policy makers need to obtain lessons from how the industry was impacted and its speed of recovery in the context of earlier epidemics for example the SARS in 2003. A lot of speculation centres around how long will the pandemic last, since it impacts consumers travel plans. It is important to mention here that the rapid expansion in GDP in the third quarter of 2003 immediately after recovery from SARS, after a declining situation in the second quarter, for example in Hong Kong, was primarily due to international tourists resuming their travel plans. A similar lesson can be learnt from the Spanish influenza (1918), for example in the context of Canada the economy's retail sales jumped to 8 per cent immediately after pandemic in January 1919, James and Sargent (2006). However, if we stick to pessimistic assumptions regarding the current situation supposing that the current morbidly rates will continue then the tourism industry will be severely impacted both from the supply and demand side. Interruptions in the flow of intermediate and allied products and shortage of labour supply would adversely hit the supply sector. Further from the demand side the adverse impact on the psychology of the consumers owing to the fear of pandemics will severely dampen tourism.

Funding It is further stated that this work has been done by the authors, Gizem Uzuner and Sudeshna Ghosh. The material of the paper is not published anywhere, nor it is under simultaneous consideration for publication in any language, it will not be presented for publication to any other publication in any language.

\section{Compliance with ethical standards}

Conflict of interest The author declare that they have no conflict of interest.

\section{Appendix}

See Appendix Table 5. 
Table 5 Variance inflation factors

\begin{tabular}{|c|c|c|c|}
\hline \multicolumn{4}{|c|}{ Date: $10 / 24 / 20$ Time: $18: 38$} \\
\hline \multicolumn{4}{|c|}{ Sample: 2000M01 2020M01 } \\
\hline \multicolumn{4}{|c|}{ Included observations: 241} \\
\hline \multirow[t]{2}{*}{ Variable } & Coefficient & Uncentered & Centered \\
\hline & Variance & VIF & VIF \\
\hline IP & $1.14 \mathrm{E}-06$ & 438.2494 & 4.686367 \\
\hline INFL & $9.19 \mathrm{E}-05$ & 11.11758 & 3.070671 \\
\hline CCI & $5.83 \mathrm{E}-05$ & $17,308.38$ & 2.566213 \\
\hline WPU & 0.000138 & 1.196231 & 1.136797 \\
\hline $\mathrm{C}$ & 0.466904 & $13,873.24$ & NA \\
\hline
\end{tabular}

\section{References}

Ahir, H., Bloom, N., Furceri, D.: The world uncertainty index. Available at SSRN 3275033 (2018). Accessed July 2020

Akadiri, S.S., Akadiri, A.C.: Examining the causal relationship between tourism, exchange rate, and economic growth in tourism island states: evidence from second-generation panel. Int. J. Hosp. Tour. Adm. 1-16 (2019). https://doi.org/10.1080/15256480.2019.1598912

Akadiri, S.S., Alola, A.A., Uzuner, G.: Economic policy uncertainty and tourism: evidence from the heterogeneous panel. Curr. Issues Tour 1-8 (2019). https://doi.org/10.1080/13683500.2019.1687662

Anoruo, E.: Testing for linear and nonlinear causality between crude oil price changes and stock market returns. Int. J. Econ. Sci. Appl. Res. 4(3), 75-92 (2011)

Arouri, M., Rault, C., Teulon, F.: Economic policy uncertainty, oil price shocks and GCC stock markets. Econ. Bull. 34(3), 1822-1834 (2014)

Aye, G.C.: Causality between economic policy uncertainty and real housing returns in emerging economies: A cross-sample validation approach. Cogent Econ. Finance 6(1), 1473708 (2018). https://doi. org/10.1080/23322039.2018.1473708

Bahmani-Oskooee, M., Saha, S.: On the effects of policy uncertainty on stock prices: an asymmetric analysis. Quant Finance Econ 3(2), 412-424 (2019). https://doi.org/10.3934/QFE.2019.2.412

Baker, S.R., Bloom, N., Davis, S.J.: Measuring economic policy uncertainty. Q. J. Econ. 131(4), 1593-1636 (2016). https://doi.org/10.1093/qje/qjw024

Baker, S. R., Bloom, N., Davis, S. J., \& Terry, S. J. (2020). Covid-induced economic uncertainty. Working Paper (No. w26983). National Bureau of Economic Research. Retrieved from https://www.nber.org/ papers/w26983

Bekiros, S., Gupta, R., Paccagnini, A.: Oil price forecastability and economic uncertainty. Econ. Lett. 132, 125-128 (2015). https://doi.org/10.1016/j.econlet.2015.04.023

Brock, W., Dechert, W., Scheinkman, J.: A test for independence based on the correlation dimension. Econometr. Rev. 15(3), 197-235 (1996). https://doi.org/10.1080/07474939608800353

Brogaard, J., Detzel, A.: The asset-pricing implications of government economic policy uncertainty. Manag. Sci. 61(1), 3-18 (2015). https://doi.org/10.1287/mnsc.2014.2044

Brooks, C.: Testing for non-linearity in daily sterling exchange rates. Appl. Financ. Econ. 6(4), 307-317 (1996). https://doi.org/10.1080/096031096334105

Chatziantoniou, I., Degiannakis, S., Eeckels, B., Filis, G.: Forecasting tourist arrivals using origin country macroeconomics. Appl. Econ. 48(27), 2571-2585 (2016). https://doi.org/10.1080/00036 846.2015 .1125434

Chisadza, C., Clance, M., Gupta, R., \& Wanke, P. (2020). Uncertainty and Tourism in Africa. Working Paper (No. 202019). https://www.up.ac.za/media/shared/61/WP/wp_2020_19.zp186750.pdf

Chow, S.C., Cunado, J., Gupta, R., Wong, W.K.: Causal relationships between economic policy uncertainty and housing market returns in China and India: evidence from linear and nonlinear panel and time series models. Stud Nonlinear Dyn Econometr 22(2) (2017). https://doi.org/10.1515/snde-2016-0121 
Christidis, P., Christodoulou, A.: The predictive capacity of air travel patterns during the global spread of the COVID-19 pandemic: risk, uncertainty and randomness. Int. J. Environ. Res. Public Health 17(10), 3356 (2020). https://doi.org/10.3390/ijerph17103356

del Mar Alonso-Almeida, M., Bremser, K.: Strategic responses of the Spanish hospitality sector to the financial crisis. Int. J. Hosp. Manag. 32, 141-148 (2013). https://doi.org/10.1016/j.ijhm.2012.05.004

Demir, E., Gozgor, G.: The impact of economic policy uncertainty on the vehicle miles traveled (VMT) in the US. Eurasian Journal of Business and Management 4(3), 39-48 (2016)

Demir, E., Ersan, O.: The impact of economic policy uncertainty on stock returns of Turkish tourism companies. Curr. Issues Tour. 21(8), 847-855 (2018)

Demir, E., Gözgör, G.: Does economic policy uncertainty affect Tourism? Ann. Tour. Res. 69, 15-17 (2018). https://doi.org/10.1016/j.annals.2017.12.005

Divino, J.A., McAleer, M.: Modelling and forecasting daily international mass tourism to Peru. Tour Manag 31(6), 846-854 (2010). https://doi.org/10.1016/j.tourman.2009.09.002

Dogru, T., Isik, C., Sirakaya-Turk, E.: The balance of trade and exchange rates: theory and contemporary evidence from tourism. Tour. Manag. 74, 12-23 (2019). https://doi.org/10.1016/j.tourman.2019.01.014

Dragouni, M., Filis, G., Gavriilidis, K., Santamaria, D.: Sentiment, mood and outbound tourism demand. Ann. Tour. Res. 60, 80-96 (2016). https://doi.org/10.1016/j.annals.2016.06.004

Euromonitor International: "Italy in crisis as tourism demand collapses amid coronavirus pandemic", 18 March 2020; Italian Federation of Tourism, "Coronavirus: Assoturismo, già bruciati 200 milioni di euro di prenotazioni per marzo. Messina: lavorare per la normalizzazione o salta tutto", 27 February 2020

Ghosh, S.: Asymmetric impact of COVID-19 induced uncertainty on inbound Chinese tourists in Australia: insights from nonlinear ARDL model. Quant. Finance Econ. 4(2), 343-364 (2020). https://doi. org/10.3934/QFE.2020016

Gössling, S., Scott, D., Hall, C.M.: Pandemics, tourism and global change: a rapid assessment of COVID-19. J. Sustain. Tour. 16(1), 1-20 (2020). https://doi.org/10.1080/09669582.2020.1758708

Gozgor, G., Demir, E.: The effects of economic policy uncertainty on outbound travel expenditures. J. Compet. 10(3), 5-15 (2018). https://doi.org/10.7441/joc.2018.03.01

Gozgor, G., Ongan, S.: Economic policy uncertainty and tourism demand: empirical evidence from the USA. Int. J. Tour. Res. 19(1), 99-106 (2017). https://doi.org/10.1002/jtr.2089

Granger, C.W., Yoon, G.: Hidden cointegration. U of California. Economics Working Paper (2002-02). http://papers.ssrn.com/sol3/papers.cfm (2002)

Hatemi-J, A.: A new method to choose optimal lag order in stable and unstable VAR models. Appl. Econ. Lett. 10(3), 135-137 (2003). https://doi.org/10.1080/1350485022000041050

Hatemi-J, A.: Forecasting properties of a new method to determine optimal lag order in stable and unstable VAR models. Appl. Econ. Lett. 15(4), 239-243 (2008). https://doi.org/10.1080/1350485050 0461613

Hatemi-J, A.: Asymmetric causality tests with an application. Empir. Econ. 43(1), 447-456 (2012). https ://doi.org/10.1007/s00181-011-0484-X

Hinich, M.J., Patterson, D.M.: Evidence of nonlinearity in daily stock returns. J. Bus. Econ. Stat. 3(1), 69-77 (1985)

Işik, C., Kasımatı, E., Ongan, S.: Analyzing the causalities between economic growth, financial development, international trade, tourism expenditure and/on the $\mathrm{CO}_{2}$ emissions in Greece. Energy Sour Part B 12(7), 665-673 (2017). https://doi.org/10.1080/15567249.2016.1263251

Iş1k, C., Radulescu, M., Fedajev, A.: The effects of exchange rate depreciations and appreciations on the tourism trade balance: the case of Spain. East. J. Eur. Stud. 10(1), 221-237 (2019)

Işı, C., Sirakaya-Turk, E., Ongan, S.: Testing the efficacy of the economic policy uncertainty index on tourism demand in USMCA: theory and evidence. Tour Econ (2019b). https://doi. org/10.1177/1354816619888346

James, S., Sargent, T. C.: The economic impact of an influenza pandemic. Canada Department of Finance (2006)

Karabulut, G., Bilginb, M.H., Demir, E., Doker, A.C.: How pandemics affect tourism: international evidence. Ann. Tour. Res. 84, 3579530 (2020)

Karnizova, L., Li, J.C.: Economic policy uncertainty, financial markets and probability of US recessions. Econ. Lett. 125(2), 261-265 (2014). https://doi.org/10.1016/j.econlet.2014.09.018

Khan, K., Su, C.W., Xiao, Y.D., Zhu, H., Zhang, X.: Trends in tourism under economic uncertainty. Tour. Econ. (2020). https://doi.org/10.1177/1354816620909608

Kuo, H.I., Chen, C.C., Tseng, W.C., Ju, L.F., Huang, B.W.: Assessing impacts of SARS and Avian Flu on international tourism demand to Asia. Tour. Manag. 29(5), 917-928 (2008). https://doi. org/10.1016/j.tourman.2007.10.006 
Madanoglu, M., Ozdemir, O.: Economic policy uncertainty and hotel operating performance. Tour. Manag. 71, 443-452 (2018). https://doi.org/10.1016/j.tourman.2018.10.012

McAleer, M., Huang, B.W., Kuo, H.I., Chen, C.C., Chang, C.L.: An econometric analysis of SARS and Avian Flu on international tourist arrivals to Asia. Environ. Model. Softw. 25(1), 100-106 (2010). https://doi.org/10.1016/j.envsoft.2009.07.015

Nguyen, C.P., Schinckus, C., Su, T.D.: Economic policy uncertainty and demand for international tourism: an empirical study. Tour. Econ. (2020). https://doi.org/10.1177/1354816619900584

OECD: Tourism policy responses to the coronavirus (COVID-19). OECD Publishing, Paris (2020). https ://www.oecd.org/coronavirus/policy-responses/tourism-policy-responses-to-the-coronavirus-covid -19-6466aa20/

Ongan, S., Gozgor, G.: Tourism demand analysis: The impact of the economic policy uncertainty on the arrival of Japanese tourists to the USA. Int. J. Tour. Res. 20(3), 308-316 (2018). https://doi. org/10.1002/jtr.2182

Papatheodorou, A., Rosselló, J., Xiao, H.: Global economic crisis and tourism: consequences and perspectives. J. Travel Res. 49(1), 39-45 (2010). https://doi.org/10.1177/0047287509355327.

Perles-Ribes, J.F., Ramón-Rodríguez, A.B., Sevilla-Jiménez, M., Rubia, A.: The effects of economic crises on tourism success: an integrated model. Tour. Econ. 22(2), 417-447 (2016). https://doi. org/10.5367/te.2014.0428

Ritchie, J.R.B., Amaya Molinar, C.M., Frechtling, D.C.: Impacts of the world recession and economic crisis on tourism: North America. J. Travel Res. 49(1), 5-15 (2010)

Rosselló, J., Santana-Gallego, M., Awan, W.: Infectious disease risk and international tourism demand. Health Policy Plan. 32(4), 538-548 (2017). https://doi.org/10.1093/heapol/czw177

Sharma, C.: Testing the asymmetric effects of the economic policy uncertainty on the tourism demand in India. Tour. Econ. (2019). 10.1177\%2F1354816619894080

Sheldon, P., Dwyer, L.: The global financial crisis and tourism: perspectives of the academy. J. Travel Res. 49(1), 3-4 (2010). https://doi.org/10.1177/0047287509353191

Shi, H., Li, X., Zhang, H., Liu, X., Li, T., Zhong, Z.: Global difference in the relationships between tourism, economic growth, CO2 emissions, and primary energy consumption. Curr. Issues Tour. 23(9), 1122-1137 (2020)

Singh, R., Das, D., Jana, R.K., Tiwari, A.K.: A wavelet analysis for exploring the relationship between economic policy uncertainty and tourist footfalls in the USA. Curr. Issues Tour. 22(15), 1789-1796 (2019). https://doi.org/10.1080/13683500.2018.1445204

Sio-Chong, U., So, Y.C.: The impacts of financial and non-financial crises on tourism: evidence from Macao and Hong Kong. Tour. Manag. Perspect. 33, 100628 (2020). https://doi.org/10.1016/j.tmp.2019.10062 8

Sokhanvar, A.: Does foreign direct investment accelerate tourism and economic growth within Europe? Tour. Manag. Perspect. 29, 86-96 (2019)

Song, H., Lin, S.: Impacts of the financial and economic crisis on tourism in Asia. J. Travel Res. 49(1), 16-30 (2010). 10.1177\%2F0047287509353190

Toda, H.Y., Yamamoto, T.: Statistical inference in vector autoregressions with possibly integrated processes. J. Econometr. 66(1-2), 225-250 (1995). https://doi.org/10.1016/0304-4076(94)01616-8

Tsui, W.H.K., Balli, F., Tan, D.T.W., Lau, O., Hasan, M.: New Zealand business tourism: exploring the impact of economic policy uncertainties. Tour. Econ. 24(4), 386-417 (2018). $10.1177 \% 2 \mathrm{~F} 1354816617731387$

UNWTO: International tourist arrivals could fall by 20-30\% in 2020. https://www.unwto.org/news/inter national-tourism-arrivals-could-fall-in-2020. Accessed 5 Apr 2020

Uzuner, G., Akadiri, S.S., Alola, A.A.: Tourist arrivals in four major economies: another side of economic policy uncertainty and fear. Environ. Sci. Pollut. Res. (2020). https://doi.org/10.1007/s11356-02009219-9

World Tourism Organization and International Labour Organization: Economic Crisis, International Tourism Decline, and its Impact on the Poor, UNWTO, Madrid (2013). https://doi.org/10.18111/97892 84414444

World Travel and Tourism Council (WTTC): https://www.wttc.org/publications/. Accessed May 2020

Wu, T.P., Wu, H.C.: Causality between European economic policy uncertainty and tourism using waveletbased approaches. J. Travel Res. 58(8), 1347-1356 (2019). https://journals.sagepub.com/author-instr uctions/JTR

Yang, Y., Zhang, H., Chen, X.: Coronavirus pandemic and tourism: dynamic stochastic general equilibrium modeling of infectious disease outbreak. Ann. Tour. Res. (2020). https://doi.org/10.1016/j.annal s.2020.102913 
Zeng, B., Carter, R.W., De Lacy, T.: Short-term perturbations and tourism effects: the case of SARS in China. Curr. Issues Tour. 8(4), 306-322 (2005). https://doi.org/10.1080/13683500508668220

Publisher's note Springer Nature remains neutral with regard to jurisdictional claims in published maps and institutional affiliations. 